\title{
A neurocognitive model of ideological thinking
}

\author{
Leor Zmigrod (1), Cambridge University
}

\begin{abstract}
AвSTRACT. Ideological behavior has traditionally been viewed as a product of social forces. Nonetheless, an emerging science suggests that ideological worldviews can also be understood in terms of neural and cognitive principles. The article proposes a neurocognitive model of ideological thinking, arguing that ideological worldviews may be manifestations of individuals' perceptual and cognitive systems. This model makes two claims. First, there are neurocognitive antecedents to ideological thinking: the brain's low-level neurocognitive dispositions influence its receptivity to ideological doctrines. Second, there are neurocognitive consequences to ideological engagement: strong exposure and adherence to ideological doctrines can shape perceptual and cognitive systems. This article details the neurocognitive model of ideological thinking and synthesizes the empirical evidence in support of its claims. The model postulates that there are bidirectional processes between the brain and the ideological environment, and so it can address the roles of situational and motivational factors in ideologically motivated action. This endeavor highlights that an interdisciplinary neurocognitive approach to ideologies can facilitate biologically informed accounts of the ideological brain and thus reveal who is most susceptible to extreme and authoritarian ideologies. By investigating the relationships between low-level perceptual processes and high-level ideological attitudes, we can develop a better grasp of our collective history as well as the mechanisms that may structure our political futures.
\end{abstract}

Key words: Ideology, political neuroscience, political cognition, ideological thinking

\section{The origins of ideological behavior}

One of the most profound insights of Hannah Arendt's The Origins of Totalitarianism (1951) is the idea that totalitarian ideologies work not simply by coercing the external behavior of citizens-they function by coercing their minds. Arendt noted that ideologies force adherents to surrender their capacity for independent thought and instead impose a compulsive, tyrannical logic on the minds of adherents. While Arendt's theories have sparked substantial debates in the social and political sciences (e.g., Benhabib, 2003; Canovan, 1994; Villa, 2000), they have been largely overlooked by cognitive science, the empirical science of thought. This disciplinary neglect is notable given the central role of thoughts and thoughtlessness in Arendt's analyses. It is therefore pertinent to use the tools of modern science to ask: Is there a relationship between ideological worldviews and the fundamental mechan-

doi: $10.1017 /$ pls.2021.10

Correspondence: Leor Zmigrod, Cambridge University. Email: lz343@cam.ac.uk isms of thought and reasoning? And if so, how deeply does the effect of ideologies penetrate into our cognitive processes?

The proposal detailed here argues that there is an underlying relationship between high-level ideologies and low-level perception and cognition that may be deeper and more complex than Arendt envisioned. It posits that individuals' private ideologies are manifestations of their perceptual and cognitive tendencies, influenced by chronic and temporary experiences. Furthermore, it suggests that strong engagement with forceful ideologies can subsequently shape perceptual and cognitive functioning. Importantly, perception and cognition here are operationalized in terms of the neuropsychological literature-that is, in terms of the way in which brains process and evaluate stimuli. It is therefore a fundamentally neurocognitive framework of ideologies, exploring how our understanding of the brain can illuminate questions such as: How are ideologies internalized by the minds of adherents? What factors increase or decrease an individual's susceptibility to ideological thinking? Does strong engagement with an ideology shape the individual's cognitive and neural functioning? 


\section{A neurocognitive model of ideological thinking}

\section{The neurocognitive model of ideological behavior}

A neurocognitive approach to the study of ideology begins from the premise that we can study ideologies in terms of their form and structure, and not purely in terms of the content of their beliefs (Zmigrod, 2020a). Hence, we can study what it means to be ideologically extreme and dogmatic without necessarily highlighting whether that belief system is left- versus right-wing, nationalistic versus globalist, or religious versus atheist. Actions and thoughts are ideological insofar as they reflect a rigid adherence to a doctrine, resistance to evidence-based belief updating, and a selective orientation in favor of fellow adherents (the in-group) and antagonistic toward non-adherents (the out-group) (Zmigrod, 2020a, 2020 b). Ideological thinking is epistemically dogmatic and interpersonally intolerant. Ideological extremism, from this perspective, is therefore a state in which individuals are dogmatic and intolerant to an extent that can facilitate a willingness to harm those who do not follow the ideology's premises, and at times even to incur personal costs for the sake of the ideology. It is possible to envision a spectrum on which some individuals are non-ideological, if they are receptive to evidence and exhibit tolerance toward dissimilar others, while others may be ideological or ideologically extreme, depending on the intensity of their dogmatic rigidity and hostility toward out-groups. ${ }^{1}$

The neurocognitive model makes two essential claims. First, it argues that there are neurocognitive antecedents to ideological thinking: the brain's neurocognitive dispositions shape its receptivity to ideological doctrines. Second, there can be neurocognitive consequences to ideological engagement: exposure and adherence to ideological doctrines can shape perceptual and cognitive systems (Figure 1).

What are neurocognitive antecedents of ideological thinking? These are neurobiologically grounded perceptual and cognitive dispositions that heighten the allure of ideological groups, doctrines, and arguments. The notion of neurocognitive antecedents builds on the

\footnotetext{
${ }^{1}$ By this account, individuals cannot be considered "ideological" if they have a conviction to be open to new evidence and to be interpersonally tolerant. Fanatical tolerance or openness is not only rare but does not merit the description of "ideological" even in cases when it exists. It only becomes ideological if one is willing to commit violence and engage in extreme acts in the name of such tolerance, and therefore no longer exhibits the supposed radical openness and aversion to doctrine.
}

fundamental insight that has emerged among cognitive scientists over the past 50 years that individuals vary in the way in which their brains process information from the environment. When presented with identical stimuli, individuals will process and physiologically react to these stimuli in different ways, based on their cognitive and neural architecture (Posner \& Rothbart, 2018; Sallis et al., 2018; Trofimova, 2016; Trofimova \& Robbins, 2016; Uher, 2018). Thus, there are neurocognitive dispositions-enduring, biologically based dispositional tendencies in processing, evaluating, and responding to stimuli-that guide individuals' behavior and decisionmaking. These neurocognitive dispositions are stable over time and typically not under explicit conscious control (Trofimova et al., 2018).

However, theories of the emergence and maintenance of ideological worldviews have not traditionally incorporated the idea of neurocognitive dispositions. Consequently, the study of ideology is now ripe for a "neurocognitive model" that emphasizes how cognitive, perceptual, and neurobiological dispositions can increase or reduce an individual's susceptibility to ideological worldviews. The neurocognitive model posits that individuals' neurobiologically grounded implicit tendencies can make them more receptive or resistant to ideological systems. It is rooted in the idea that information-processing strategies evident in ideologically neutral contexts will also seep into the strategies used to process ideological arguments; hence, we can begin to characterize the properties of the "ideological brain."

The idea that there are individual differences that confer susceptibility or resistance to ideological doctrines is not new. Nonetheless, past research has avoided making the strong claim that these individual differences have a biological and neurocognitive character. It is possible to observe that individuals differ in their susceptibility to ideological processes in the theories and experiments of the early days of social psychology. In the classic social psychological paradigms of social conformity and obedience to authority of the mid-twentieth century by Asch (1956), Milgram (1963, 1974), Festinger (1950, 1954), and others, there was always a percentage of participants who resisted conformity or obedience (even in studies with small participant samples; see Blass, 1991; Haslam \& Reicher, 2017; Martin \& Hewstone, 2001). The percentage of resisting participants oscillated between $10 \%$ and $30 \%$ according to the specific experimental paradigm, but overall, some participants always rebelled - there were consistent outliers to universal authoritarian tendencies. This mirrored the historical reality that in 


\section{Leor Zmigrod}
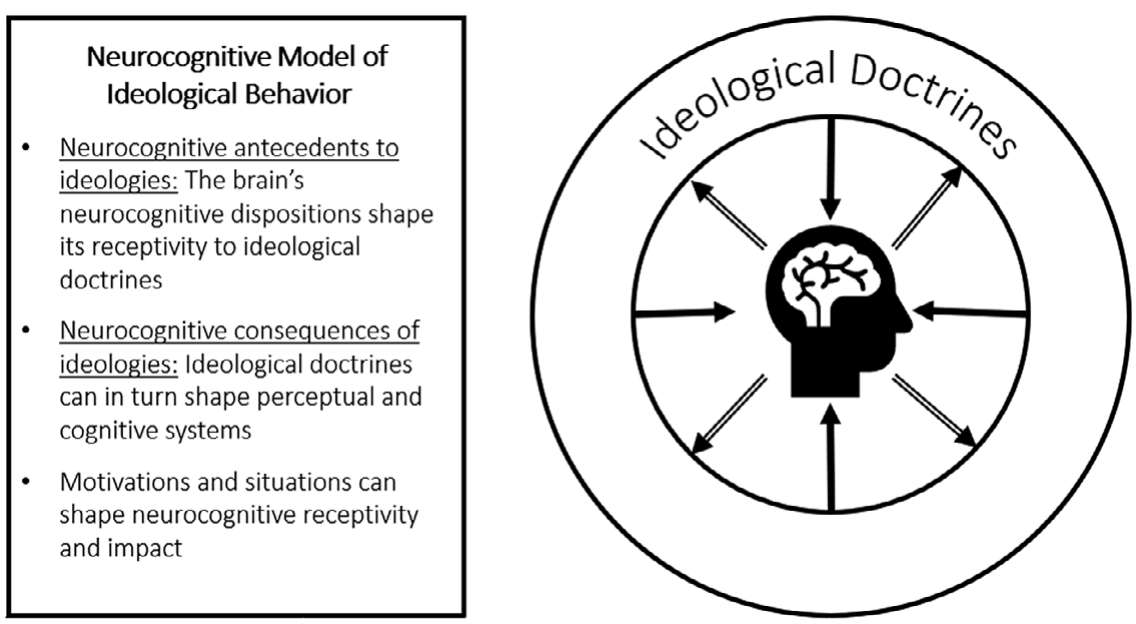

Figure 1. Outline of the neurocognitive model of ideological behavior.

contexts of conflict, war, and genocide, (1) some individuals are more resistant to ideological systems that promote dogmatism and out-group hostility, and (2) some individuals tend to display greater receptivity to ideological systems (Zmigrod, 2020a).

Indeed, social scientists have frequently noted that not all individuals are equally likely to internalize ideologies and adhere to them in an extreme fashion. In their pioneering book The Authoritarian Personality, Theodor Adorno and colleagues (1950) asked "why is it that certain individuals accept [fascist] ideas while others do not?” (p. 3). Soon afterward, in 1955, psychologist Richard Crutchfield posed a similar question about conformity: "what traits of character distinguish between those [people] exhibiting much conformity behavior ... and those exhibiting little conformity?" (p. 194). Building on these ideas, the sociologist Edward Shils (1958) noted that individuals are differentially susceptible to ideological doctrines, and this is not purely a matter of upbringing or socioeconomic context: "not all those who live in a broken and disadvantaged condition are drawn equally by the magnet of the ideological orientation" (pp. 463-464). Social psychologist Thomas Blass (1991) further highlighted the presence of interpersonal variation in ideological and authoritarian processes: "that there are individual differences in obedience is a fact because in most obedience studies, given the same stimulus situation, one finds both obedience and disobedience taking place" (p. 402). The recognition that there is variability in tendencies to conform, obey, and adhere to ideological dogmas is therefore at least 70 years in the making-but here it is proposed that we can shed light on these individual differences by adopting a neurocognitive model of ideological behavior.

As noted earlier, the neurocognitive model also makes a second claim: it argues that there are neurocognitive consequences to ideological engagement. That is, deep attachment and adherence to ideological doctrines and groups can have an impact on the brain. This claim originates from the well-established notion that the brain easily forms habits when exposed to particular experiences and reinforcement environments (e.g., Caspi \& Moffitt, 2006; Leong et al., 2017; Robbins \& Costa, 2017). The concept of brain plasticity reflects the rich neuroscientific understanding that experience can fundamentally change the structure and function of cerebral neurons, and so the brain is highly responsive to the properties of its environment (Lewkowicz \& Ghazanfar, 2009; McEwen, 2012; Sale et al., 2014).

We can consider dogmatic ideological contextswhich espouse a rigid doctrine, resistance to evidencebased belief updating, and strict boundaries between social groups (Zmigrod, 2020a) —as such neurocognitively influential environments. Repeated exposure to dogmatic and parochial ideological contexts is therefore likely to shape general, non-ideological information-processing strategies. In the same way that harsh parental and socioeconomic environments can alter genetic expression (Borghol et al., 2012; Essex et al., 2013), cognition (Everson-Rose et al., 2003; Kaplan et al., 2001), physiology (Friedman et al., 2015; Gruenwald et al., 2012; Hagan et al., 2016), and even physical health (Springer et al., 2007; Wickrama et al., 2005), ideologies can impact the way in which the mind processes information and 

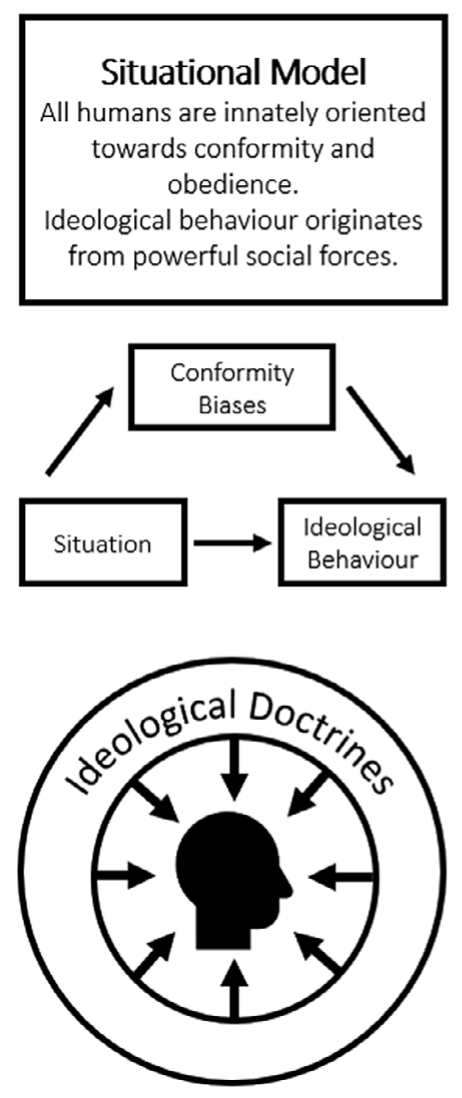
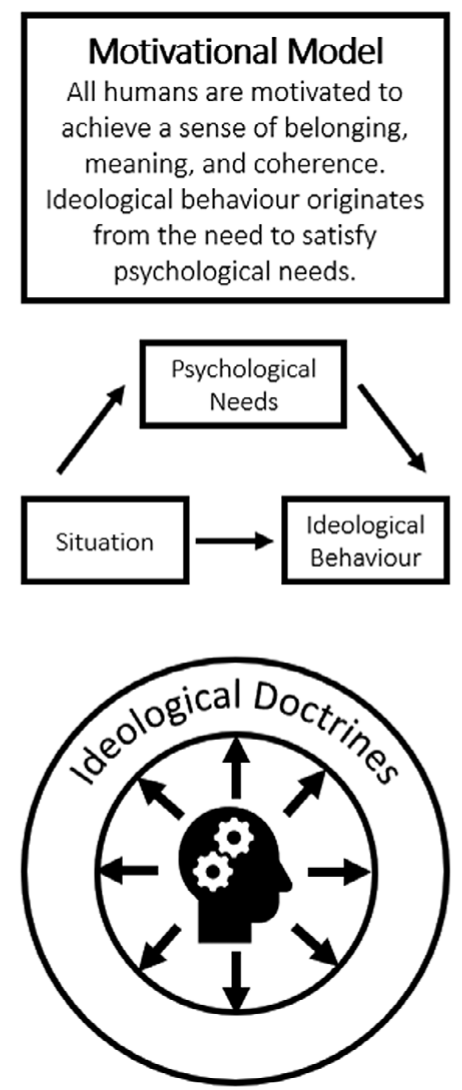

Neurocognitive Model

Humans differ in their susceptibility to ideologies due to variations in neurocognition.

Ideological behaviour reflects experience-shaped neurocognitive processes.
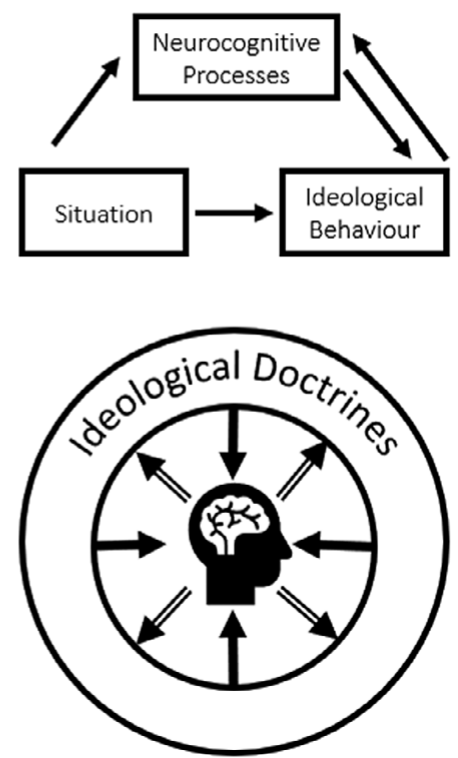

Figure 2. Summaries of the premises, assumptions, and essential causal relations posited by the (A) situational model, (B) motivational model, and (C) neurocognitive model of ideological behavior. Each model gives a different weight to the role of the mind and brain in shaping ideological attitudes (increasing from left to right), and each model makes different assumptions about how external situations shape ideological behavior.

perceives stimuli. As noted in the social cognition literature, "the structure of the shared external environment shapes neural responses and behaviour" (Hasson et al., 2012, p. 120). Compelling collective ideologies often impose a powerful structure on the social and personal environment (Zmigrod, 2020a), and so their devout adoption can have substantial downstream effects on the brain. This extends the claims made by political philosophers such as Arendt into new territory: ideologies can have a profound impact on the minds of adherents by shaping their neural and cognitive functioning.

\section{The roles of situations and motivations}

The neurocognitive model of ideological behavior proposed here builds upon-but departs markedly from-two dominant schools of thought that have historically characterized the study of ideologically motivated action (see Figure 2). The first, which we can call the "situational" model, posits that under certain conditions, anybody would commit atrocities in the name of an ideological group or cause. That is, sufficiently forceful social situations will spur humans to conform and obey authority and, in turn, numb their capacities for independent reasoning and judgment. The situational model proposes that sufficiently forceful situations will homogenize differences between individuals and produce authoritarian, dogmatic, and self-sacrificial collectives (see Figure 2A). This model gained prominence in the shadow of the totalitarian regimes of the twentieth century and helped alleviate concerns that particular historical groups have an innate capacity for evil. It places universal human biases at its core and leaves little room for individual differences in receptivity to ideological systems. It is also consistent with models in political science that emphasize the strong role of environmental socialization on the formation of political orientations (e.g., Campbell et al., 1960; Hyman, 1959; Zaller, 1992). 


\section{Leor Zmigrod}

The second account can be summarized as the "motivational" model, which espouses that dogmatic and parochial ideological behavior is the result of the activation of relational, existential, or epistemic motivations. The motivational model was influenced by psychoanalytic traditions that considered belief and behavior as fundamentally sculpted by unconscious needs and desires. It therefore suggests that "ideological belief systems reflect motivational concerns" (Jost et al., 2008, p. 134), such as the need to belong, to attain meaning, and to possess a coherent explanation of the world (see Figure 2B). In accordance with Freudian and psychoanalytic thought, Adorno and colleagues (1950) set the tone for the field by discussing susceptibility to ideologies in terms of needs and motivations: "ideologies have for different individuals, different degrees of appeal, a matter that depends upon the individual's needs and the degree to which these needs are being satisfied or frustrated" (p. 2). The language of needs and motivations has persisted as the primary lens through which ideological processes are discussed in the academic literature. This has had a powerful effect on how the psychological roots of ideologies have been conceptualized, operationalized, and measured: prevailing theories of the psychology of various ideologies and associated processes, such as conservatism (Jost et al., 2003), religious fundamentalism (Hill \& Williamson, 2005), authoritarianism (Adorno et al., 1950), system justification (Jost \& Banaji, 1994), and violent radicalization (Kruglanski et al., 2014), have been explicitly motivational accounts. Nevertheless, the robust cognitive scientific understanding that human behavior is not solely determined by needs and motivations suggests that purely motivational accounts of the emergence and maintenance of ideological worldviews may be insufficient.

In contrast with the situational and motivational accounts, the neurocognitive model argues that ideological worldviews reflect cognitive and perceptual tendencies, and, in turn, ideologies can influence low-level neurocognitive processes (Figure 2C). It therefore considers ideological thinking as neurocognitively negotiated, rather than the product of authoritarian situations or psychological needs. Nonetheless, the neurocognitive model still makes room for the effect of situations and motivations. Situations that elicit stress or strong social pressure can amplify neurocognitive processes (e.g., Lupien et al., 2007; Schoofs et al., 2008) that guide individuals-to different degrees-to behave in ideological ways. For example, a stressful situation can impair cognitive flexibility and executive function
(Alexander et al., 2007; Plessow et al., 2011; Schoofs et al., 2008) and thereby produce ideologically rigid behavior and make the individual receptive to propaganda. Similarly, the activation of motivations such as epistemic needs to attain coherence can shape information processing and working memory in motivationconsistent directions (Lassiter et al., 1991; Locke, 2000; Verplanken, 1993). For instance, epistemic motivations for coherence can influence the perceptual interpretation of data (den Ouden et al., 2012 Dijksterhuis et al., 1996), or existential motivations to attain meaning can make attentional processes attuned to meaning-producing information (Pessoa, 2009; Pessoa \& Engelmann, 2010; Thórisdóttir \& Jost, 2011). Careful attention to cognitive mechanisms can also shine a light on phenomena such as the uncertainty paradox (Haas \& Cunningham, 2014), whereby threat modulates the extent to which uncertainty breeds tolerance or intolerance: when conditions are safe, uncertainty can elicit an exploratory stance that facilitates political tolerance, whereas when conditions are threatening, uncertainty can lead to closed-mindedness. Incorporating physiological frameworks for how threat shapes cognition can help provide a more biologically grounded explanation for these context-dependent effects.

The neurocognitive model can also inform work on the genetic heritability of ideological beliefs (Hatemi et al., 2013; Hatemi et al., 2014; Israel et al., 2015) by positing specific mechanisms through which genetic variations contribute to neurocognitive differences and thus ideological attitudes. It thus is able to posit mechanistic theories about how biological processes shape ideological worldviews. Moreover, the situational and motivational models assume unilateral effects: the situational model views situations as imposing themselves on the individual (Figure 2A), and the motivational model sees the individual's needs as stimulating the expression of ideological thought (Figure 2B). In contrast, the neurocognitive model explicitly postulates that there are bidirectional processes between the ideological environment and the brain (Figure 2C).

\section{Empirical support for the neurocognitive model}

Evidence for the neurocognitive antecedents and consequences of ideologies can be found in the burgeoning fields of political neuroscience and experimental social psychology. Recent work has revealed that ideologically neutral cognitive and perceptual decision-making 


\section{A neurocognitive model of ideological thinking}

processes are related to higher-level ideological convictions and beliefs (Rollwage et al., 2018; Rollwage et al., 2019; Zmigrod et al., 2018; Zmigrod, Rentfrow, \& Robbins 2019; Zmigrod, Rentfrow, Zmigrod, \& Robbins 2019; Zmigrod, Zmigrod, Rentfrow, \& Robbins 2019; Zmigrod, 2020b). Three cognitive traits that have been recently shown to confer susceptibility to ideological thinking are particularly noteworthy: (1) cognitive inflexibility, (2) impaired metacognitive awareness, and (3) slower perceptual evidence accumulation processing. First, there is evidence that a tendency toward mental rigidity can foster ideological rigidity. Cognitive inflexibility-operationalized as a difficulty with switching between modes of thinking and adapting to changing environmental contingencies-has been implicated in extreme ideological identities (for a review, see Zmigrod, 2020b) in the context of politics (Zmigrod et al., 2020), nationalism (Zmigrod, Rentfrow \& Robbins, 2018), religion (Zmigrod, Rentfrow, Zmigrod, \& Robbins, 2019), dogmatism (Zmigrod, Zmigrod, Rentfrow, \& Robbins, 2019), and a willingness to endorse violence and self-sacrifice (Zmigrod, Rentfrow, \& Robbins, 2019b). In these studies, cognitive inflexibility was measured with objective behavioral tests of executive function and perception, and so the findings are not susceptible to the problems of self-report personality surveys, in which there can be biases of socialdesirability, self-perception, and social norms. The rigidity with which individuals perceive and process stimuli generally was thus linked to the rigidity of their ideological beliefs. Hence, these findings demonstrate that dispositions in implicit information-processing tendencies may be tied to high-level explicit ideological worldviews.

Second, recent cognitive research has illustrated a relationship between impaired metacognition-the awareness of one's cognitive processes-and ideological dogmatism on both the political left and right (Rollwage et al., 2018). Here, too, the researchers employed neuropsychological paradigms and computational models to reveal differences between individuals who were ideologically moderate versus extreme. Individuals who were ideologically extreme were characterized by impaired metacognition, suggesting that individuals' capacity to be aware of and to regulate their cognitive functioning may confer susceptibility to internalizing ideologies. There is growing empirical support for the idea that resistance to evidence in the sociopolitical sphere may therefore emerge from a neurocognitive impairment in metacognitive processes (Fischer et al., 2019; Heyes et al., 2020; Kleitman et al., 2019; Morris et al., 2019; Rollwage et al., 2019; Sinclair et al., 2019).

Another example of the neurocognitive correlates of ideological worldviews lies in the study of perceptual processes. Recent research examining the cognitive signatures of a range of ideological attitudes found that impairments in strategic information processing were linked to more authoritarian, conservative, nationalistic, and religious tendencies (Zmigrod et al., 2021). This was manifest in implicit behavioral paradigms that measure performance on executive functioning tasks associated with working memory and planning. The findings could indicate that difficulty in planning and executing complex action sequences in basic perception increases people's reliance on coherent collective dogmas that simplify the world into absolute explanations and clear behavioral prescriptions. Furthermore, the study revealed that slower evidence accumulation of perceptual data (on the order of milliseconds) predicts a dogmatic thinking style (Zmigrod et al., 2021). This analysis tapped into low-level neurocognitive processes by relying on drift-diffusion modeling of trial-by-trial performance on two-forced choice tasks. Notably, dogmatic individuals also exhibited tendencies toward impulsivity, suggesting that dogmatism may arise out of a cognitive style characterized by premature decisions based on imperfectly processed evidence. Dogmatism in evaluating evidence could therefore reflect the individual's impairments in processing perceptual evidence. Moreover, the analysis suggested that response caution-defined as the trade-off between accuracy and speed (with a preference for accuracy, in tasks where both speed and accuracy are rewarded)—was related to more socially conservative and nationalistic worldviews. Cautious perceptual strategies may therefore percolate to cautious (i.e., conservative) ideological beliefs. Studying the relationship between ideological attitudes and individual differences in lowlevel perceptual and cognitive processing can therefore help illuminate the character of the ideological brain.

Importantly, the cognitive traits that confer susceptibility to thinking ideologically manifest in simple neuropsychological and perceptual tasks which are ideologically neutral and occur on time scales that are much faster (in the order of milliseconds) than those during which ideological attitudes are formed. This is suggestive of domain-general and time-invariant processes and strategies that operate on multiple time scales and across a variety of contexts.

This idea is commensurate with, and supported by, extant research in biopolitics indicating physiological 


\section{Leor Zmigrod}

differences between political liberals and conservatives (e.g., Ahn et al., 2014; Arceneaux et al., 2018; Friesen et al., 2020; Hibbing, Smith, \& Alford, 2014; Hibbing, Smith, Peterson, \& Feher, 2014; for a recent review, see Smith \& Warren, 2020). The guiding theoretical assumption behind much of the psychophysiological and neuroscientific research on political orientation is that certain kinds of implicit, automatic emotional reactivities-which can be evident across multiple timescales and in diverse stimulus domains-underpin individuals' political tendencies. The neurocognitive model of ideological thinking can assimilate these findings and perhaps offer a framework through which to ask about the potential bidirectional relationship between physiological traits and ideological immersion. What baseline individual differences-coded by genetic markers-contribute to susceptibility to ideological thinking? And how do strong ideological environments shape an individuals' physiological reactivity? Addressing the potential bidirectionality of these effects over time, as well as the need to study ideological thinking, dogmatism, and extremism beyond purely the classic left/right political divide, is essential to understand these ideological and neurocognitive phenomena in an ecologically valid way. Appreciating, and conceptually separating, the antecedents and consequences of ideological behavior on the mind may be a critical avenue forward that could help resolve some empirical inconsistencies (Smith \& Warren, 2020) in the political psychophysiology field. This will also be supported by drawing on research from adjacent disciplines which highlights humans' capacity for neuroplasticity and the fact that neurocognition can be fundamentally shaped by environments (Blix et al., 2013; Boyke et al., 2008; Creswell et al., 2016; Draganski et al., 2004; Hölzel et al., 2009; Maguire et al., 2000)—and so ideological environments also need to be taken seriously as such cognitively influential environments. ${ }^{2}$

Indeed, research from the cognitive science of religion (Barrett, 2000; Bering, 2006; Norenzayan \& Shariff, 2008; Sosis \& Alcorta, 2003) has illustrated the neurocognitive consequences of ideological engagement. Religion is a useful ideological candidate because of the intensity of its rituals and the variability in religious practices. This line of work has demonstrated that repetitive adherence to religious practices appears to shape visual perception, neurophysiology, and meta-control

\footnotetext{
${ }^{2}$ This also highlights the challenges of identifying "left-wing" environments that are equally psychologically coercive as more conservative ideological environments.
}

cognitive policies. For instance, hierarchical visual perception of atheists has been shown to differ from that of neo-Calvinists (Colzato et al., 2008; Colzato, van Beest, et al., 2010), Italian Roman Catholics (Colzato, van Beest, 2010), Orthodox Jews (Colzato, van Beest, 2010a), and Taiwanese Zen Buddhists (Colzato, Hommel, et al, 2010). There are subtle differences in the visual attentional styles of these different religious groups that parallel the doctrine they espouse, suggesting that religious adherence can fundamentally shape visual attention (Hommel \& Colzato, 2010, 2017). This faithspecific modulation of cognition has also been extended to other types of cognitive and attentional processes, such as temporal discounting (Paglieri et al., 2013), conflict detection (Pennycook et al., 2014), and action control (Hommel et al., 2011). Anxious attachment styles have also been linked to conspiratorial beliefs, highlighting the plausible relationship between internal working models of the unpredictability of the world that emerge from early childhood experiences and later conspiratorial ideation (Green \& Douglas, 2018). These findings are correlational and so longitudinal research is necessary to clearly delineate the causal arrows. Notably, in the domain of cognitive flexibility, Zmigrod, Rentfrow, Zmigrod, and Robbins (2019) examined participants who had a religious upbringing and those who did not and compared individuals who had "entered" or "exited" religion as well as those who had remained atheistic or religious with respect to their upbringing. Although current religious affiliation was a stronger predictor of cognitive rigidity than past upbringing, a trend did emerge such that nonreligious participants who had a religious upbringing (those who "left" religious ideologies for atheism) were the most cognitively flexible (Zmigrod, Rentfrow, Zmigrod, \& Robbins, 2019). The decision to move away from a powerful ideological environment can therefore require substantial cognitive flexibility and effort. Additional research with a longitudinal or temporal dimension will allow for clearer dissection of the causal arrows in such cases, possibly by accounting for the intensity or devoutness of the ideological environment, which is not equivalent across all individuals who grow up in religious contexts.

Furthermore, neuroscientists have posited that religion may serve as a neural antidote to anxiety and uncertainty (Inzlicht et al., 2011). Correspondingly, it has been shown that invoking religious concepts can alter the neurophysiological error-monitoring of religious participants. Specifically, amongst religious believers, contemplating religious thoughts (such as God's 


\section{A neurocognitive model of ideological thinking}

love) can dampen error-related negativity, a neural signal that emerges from the anterior cingulate cortex that is implicated in monitoring performance and affective response to errors (Good et al., 2015). Moreover, greater religious zeal-a fanatic form of belief-was associated with lower error-related negativity when completing a perceptual Stroop task (Inzlicht et al., 2009), corroborating the idea that religion can act as an anxiety-reducing palliative because of its general epistemic and meaningcreating properties (Inzlicht et al., 2011). It is important to qualify these findings and address the potential bidirectionality of these effects; religious exposure can shape individuals' neurocognition and, at the same time, neurocognitive predispositions can influence the type and level of zeal with which individuals adhere to the religious ideology. Consequently, while religion offers a valuable test case for the impact of ideologies on the brain, processes of ideological self-selection must be considered as well.

Research on conspiracy theories has also productively examined how perceptual and cognitive processes can give rise to conspiratorial or supernatural beliefs (Douglas \& Sutton, 2018). Examining the relationship between illusory pattern perception and conspiratorial beliefs, van Prooijen and colleagues (2018) found that seeing patterns in chaotic visual stimuli is related to more irrational beliefs. In addition, following a manipulation that strengthened belief in a conspiracy theory, participants perceived world events as though they were more strongly causally connected. It is therefore possible to trace a relationship between pattern perception-even in the domain of vision-and how that relates to adoption of ideological orientations that reflect dogmatic, evidence-resistant (or evidence-distorting) ways of thinking about the world. Conspiracy theories frequently emerge in new, mutating forms, and so can be sufficiently malleable for intervention studies that either challenge or confirm conspiratorial ideation, or that alter the psychological state of the participant (Sullivan et al., 2010; van Prooijen \& Acker, 2015), allowing researchers to identify the cognitive and perceptual consequences of such ideological exposure.

A similar strand of research that focuses on general personal ideals and values (McGregor et al., 2001; McGregor et al., 2010) rather than specific political or religious ideologies has shown that when individuals are asked to consider how their ideals generate personal conflicts (versus just thinking about the subjective importance of these ideals), they perform more poorly on cognitive tasks requiring self-regulation (Alquist et al., 2018). It is therefore essential to acknowledge the bidirectional links between situations that promote ideological thinking and cognitive processes such as selfcontrol, emotion regulation, and error-prone behavior.

Indeed, neuroscientific research on religion (Inzlicht et al., 2011; van Elk \& Aleman, 2017), politics (Haas et al., 2020; Jost et al., 2014), and social identities (Decety et al., 2018; Molenberghs \& Louis, 2018) has begun to elucidate the neural correlates of ideological engagement, adherence, and experience. This research has taken the form of lesion studies of traumatic brain injury patients-illustrating that selective lesions to certain brain regions can elevate the experience of religious fundamentalism and mystical experiences (Cristofori et al., 2016; Zhong et al., 2017). There are also structural neuroimaging studies demonstrating that brain regions such as the bilateral amygdala (Nam et al., 2018) and the anterior cingulate cortex (Kanai et al., 2011) may have structurally different forms in people with different ideological worldviews. Functional neuroimaging studies with functional magnetic resonance imaging (fMRI) and electroencephalogram (EEG) are also revealing the impact of political ideology (Haas et al., 2017; Schreiber et al., 2013), intergroup threat (Chang et al., 2016; Hein et al., 2018; Richins et al., 2019), social power (Schmid et al., 2017), and race (Hughes et al., 2019; Krosch \& Amodio, 2019) on neurocognitive processes and sensory perception. In a notable study by Schreiber and colleagues (2013), participants completed a risk-taking task while in the brain scanner. Although liberals and conservatives exhibited similar performance on the task, there were differences in the brain activation during the task, suggesting that neuroscientific methods can illuminate unobservable differences in the employment of cognitive processes.

\section{Future directions}

It will be essential for a mature neurocognitive model of ideological behavior to address the neurocognitive impacts of both holding certain ideological beliefs (Connors \& Halligan, 2015) and holding any belief to an extreme degree (Rollwage et al., 2019; Zmigrod, 2020b; Zmigrod \& Goldenberg, 2021). Furthermore, as outlined in Figure $2 \mathrm{C}$, the neurocognitive model explicitly postulates that there are bidirectional links between ideologies and neurocognitive processes, and so future research will need to untangle the causal arrows and cyclical effects between ideological and cognitive 


\section{Leor Zmigrod}

phenomena. This echoes the so-called chicken-and-egg problem in political neuroscience, which highlights the difficulty of understanding whether political or psychological processes precede each other (Jost et al., 2014) and when they compound each other.

Methodologically, the most rigorous paradigm for disentangling the "neurocognition $\rightarrow$ ideology" equation versus the "ideology $\rightarrow$ neurocognition" equation are longitudinal experimental designs. Longitudinal and panel designs facilitate the evaluation of how baseline neurocognitive functions predict ideological attitudes over time and whether adopting these ideological attitudes to a strong and passionate degree affects the brain. Sensitivity to measurement methods will be critical here - simply asking people about their support for or antagonism to welfare benefits, for example, is unlikely to yield significant (or interesting) findings, but measuring the intensity of their partisan identities (e.g., Zmigrod, Rentfrow, \& Robbins, 2020) or the extent to which they would be willing to endorse violence or self-sacrifice for a cause (e.g., Zmigrod, Zmigrod, Rentfrow, \& Robbins 2019) would be more potent and psychologically meaningful measures.

Where longitudinal designs are not feasible, it is important to isolate what is theoretically expected to be a stable baseline psychological trait (at least within the time span of an experimental session) - which should be resistant to manipulations-and what is potentially variable and amenable to manipulations. Goudarzi and colleagues (2020) offered a clever experimental paradigm that exemplifies a thoughtful distinction between stable traits and manipulable psychophysiological processes by evaluating how individual differences in ideological support for economic system justification determine the affect and autonomic arousal individuals experience when witnessing videos of inequality. This highlights how ideology impacts neurocognitive processes (tapping into the "ideology $\rightarrow$ neurocognition" equation); but, at the same time, given that this was not an experimental study requiring manipulation, alternative causal directions-whereby there is a psychological self-selection toward certain ideologies-need to be empirical and theoretically addressed. Another excellent example of this careful attention to experimental design is a ground-breaking study by Krosch and Amodio (2019). The researchers used EEG and fMRI to demonstrate that under conditions of scarcity, White participants exhibit deficits in face processing such that Black faces are visually encoded less accurately as human faces. By adapting a common resource allocation task and incorporating measures of facial processing under conditions of scarcity and nonscarcity, Krosch and Amodio were able to show how situational conditions can moderate the relationship between neurocognitive processes and ideological phenomena (tackling the "neurocognition $\rightarrow$ ideology" equation, with attention to the interaction with situations). Thoughtful experimental design can therefore disambiguate between the directionality of such causal relationships and delineate the conditions under which they operate.

Isolating the causal directions, as well as the feasibility of measuring the neural and behavioral manifestations of ideological thought, can also falsify certain hypotheses within the "neurocognition $\rightarrow$ ideology" or "ideology $\rightarrow$ neurocognition" equation. A recent study by Bakker and colleagues (2020) found that conservatives and liberals exhibit similar physiological responses to threats-despite prominent earlier studies suggesting neurophysiological differences (Oxley et al., 2008). This productive replication attempt raises a multitude of questions about the impact of ideologies on neurophysiology and highlights the importance of methodologically sound scientific endeavors to explore theoretical claims. It illustrates that there may be critical specificities in the kind of neurocognitive and physiological processes that are shaped by ideology, and points to the importance of careful assessment of potential situational moderators or other psychological individual differences. The neurocognitive model of ideological thinking can therefore provide a useful framework for conceptualizing such research and offer a theoretical platform for potential falsifications or empirical modifications of the links between ideology and neurocognitive processes.

\section{Conclusions}

"What totalitarian ideologies therefore aim at is not the transformation of the outside world ... but the transformation of human nature itself," Arendt wrote in The Origins of Totalitarianism (1951, p. 458). She thus captured a crucial idea that has often been overlooked in the social and political sciences-to understand ideologies we must examine their effects on unobservable cognitive processes and not simply observable behavior and external political structures. The neurocognitive model of ideological thinking proposed here elaborates on the underlying mechanisms by which ideologies attract and compel the minds of followers. It 


\section{A neurocognitive model of ideological thinking}

posits that individuals' ideological worldviews can reflect their existing neurocognitive dispositions and that ideological systems can shape low-level perceptual and cognitive systems. Temporary or chronic experiences of stress, intergroup conflict, or motivational crises in meaning can amplify or alter the expression of neurocognitive processes, and thus shape ideological behavior. Hence, while it may be insufficient to concentrate solely on (1) the roles of forceful homogenizing situations (i.e., the "situational" model of ideological behavior) or (2) the motivational basis of ideological action (i.e., the "motivational" model), we can develop a comprehensive framework by integrating these ideas through the insights of cognitive psychology and neurobiology.

A neurocognitive model of ideologically motivated thoughts and actions therefore has the power to illustrate that ideological positions have neurobiological foundations and synthesize the array of recent neuroscientific and cognitive research under testable theories and hypotheses (Alford et al., 2005; Batrićević \& Littvay, 2017; Fowler et al., 2008; Hatemi \& McDermott, 2012a, 2012b; Ksiazkiewicz \& Krueger, 2017; Leong et al., 2020; Nam et al., 2017; Zmigrod \& Tsakiris, 2021). The model is sensitive to causal relationships, aware of bidirectional links between environments and mental processes, and able to give a language of mediating (Ksiazkiewicz et al., 2016; Oskarsson et al., 2015) and moderating mechanisms to the complex research on the genetics of ideological orientations (e.g., Dawes \& Weinschenk, 2020; Hatemi et al., 2014; Twito \& KnafoNoam, 2020). In what ways do genes that shape cognition and perception have downstream effects to ideological behavior? Do genes that code for environmental reactivity make an individual particularly susceptible to compelling ideological movements? Breaking down the heritability of political ideology-and evaluating other aspects of ideology such as dogmatism, extremity, and interpersonal hostility-will allow for a more informative biology of ideology. Notably, research from within the biopolitics field has illustrated that attributing ideological processes to biology can help promote political tolerance (Baker \& Haas, 2020; however, see Suhay et al., 2017); conducting this science can therefore have positive spillovers into the wider world.

Cutting-edge research at the intersection of the political and biological sciences is now enabling us to ask new questions. What neurobiological factors determine an individual's receptivity or resistance to ideological systems? What are the neurocognitive advantages and dangers of strong engagement with ideologies? And when does the mission of the ideology matter? These socially pertinent questions have the power to augment our grasp both of politics and of the brain, and to elucidate the nature of the "ideological brain." A neurocognitive approach to ideologies will therefore allow us to explore timeless paradoxes as well as the origins of contemporary social issues-paving the way for an informed and informative understanding of the roles of biology and experience in shaping citizens' private ideological beliefs.

\section{References}

Adorno, T. W., Frenkel-Brunswik, E., Levinson, D. J., \& Sanford, R. N. (1950). The authoritarian personality. Harper.

Ahn, W. Y., Kishida, K. T., Gu, X., Lohrenz, T., Harvey, A., Alford, J. R., Smith, K. B., Yaffe, G., Dayan, P., \& Montague, P. R. (2014). Nonpolitical images evoke neural predictors of political ideology. Current Biology, 24(22), 2693-2699.

Alexander, J. K., Hillier, A., Smith, R. M., Tivarus, M. E., \& Beversdorf, D. Q. (2007). Beta-adrenergic modulation of cognitive flexibility during stress. Journal of Cognitive Neuroscience, 19(3), 468-478.

Alquist, J. L., Baumeister, R. F., McGregor, I., Core, T. J., Benjamin, I., \& Tice, D. M. (2018). Personal conflict impairs performance on an unrelated self-control task: Lingering costs of uncertainty and conflict. Journal of Experimental Social Psychology, 74, 157-160.

Arceneaux, K., Dunaway, J., \& Soroka, S. (2018). Elites are people, too: The effects of threat sensitivity on policymakers' spending priorities. PLOS ONE, 13(4), e0193781.

Arendt, H. (1951). The origins of totalitarianism. Meridian.

Asch, S. E. (1956). Studies of independence and conformity: I. A minority of one against a unanimous majority. Psychological Monographs: General and Applied, 70(9), 1-70.

Baker, M., \& Haas, I. J. (2020, October 26). Biological attributions for political ideology decrease political prejudice and intolerance. https://doi.org/10.31234/osf.io/pkjh7

Bakker, B. N., Schumacher, G., Gothreau, C., \& Arceneaux, K (2020). Conservatives and liberals have similar physiological responses to threats. Nature Human Behaviour, 4(6), 613-621.

Barrett, J. L. (2000). Exploring the natural foundations of religion. Trends in Cognitive Sciences, 4(1), 29-34.

Batrićević, N., \& Littvay, L. (2017). A genetic basis of economic egalitarianism. Social Justice Research, 30(4), 408-437.

Benhabib, S. (2003). The reluctant modernism of Hannah Arendt. Rowman \& Littlefield. 


\section{Leor Zmigrod}

Bering, J. M. (2006). The folk psychology of souls. Behavioral and Brain Sciences, 29(5), 453-462.

Blass, T. (1991). Understanding behavior in the Milgram obedience experiment: The role of personality, situations, and their interactions. Journal of personality and social psychology, 60(3), 398.

Blix, E., Perski, A., Berglund, \& Savic, I. (2013). Long-term occupational stress is associated with regional reductions in brain tissue volumes. PLOS ONE, 8(6), e64065.

Borghol, N., Suderman, M., McArdle, W., Racine, A., Hallett, M., Pembrey, M., ... \& Szyf, M. (2012). Associations with early-life socio-economic position in adult DNA methylation. International journal of epidemiology, 41(1), 62-74.

Boyke, J., Driemeyer, J., Gaser, C., Buchel, C., \& May, A. (2008). Training-induced brain structure changes in the elderly. Journal of Neuroscience, 28, 7031-7035.

Campbell, A., Converse, P., Miller, W., \& Stokes, D. (1960). The American voter. John Wiley \& Sons.

Canovan, M. (1994). Hannah Arendt: A reinterpretation of her political thought. Cambridge University Press.

Caspi, A., \& Moffitt, T. E. (2006). Gene-environment interactions in psychiatry: Joining forces with neuroscience. Nature Reviews Neuroscience, 7(7), 583-590.

Chang, L. W., Krosch, A. R., \& Cikara, M. (2016). Effects of intergroup threat on mind, brain, and behavior. Current Opinion in Psychology, 11, 69-73.

Colzato, L. S., Hommel, B., van den Wildenberg, W. P., \& Hsieh, S. (2010). Buddha as an eye opener: A link between prosocial attitude and attentional control. Frontiers in Psychology, 1, 156.

Colzato, L. S., van Beest, I., van den Wildenberg, W. P., Scorolli, C., Dorchin, S., Meiran, N., Borghi, A. M., \& Hommel, B. (2010). God: Do I have your attention? Cognition, 117(1), 87-94.

Colzato, L. S., van den Wildenberg, W. P., \& Hommel, B. (2008). Losing the big picture: How religion may control visual attention. PLOS ONE, 3(11), e3679.

Connors, M. H., \& Halligan, P. W. (2015). A cognitive account of belief: A tentative road map. Frontiers in Psychology, 5, 1588.

Creswell, J. D., Taren, A. A., Lindsay, E. K., Greco, C. M., Gianaros, P. J., Fairgrieve, A., Marsland, A. L., Brown, K. W., Way, B. M., Rosen, R. K., \& Ferris, J. L. (2016). Alterations in resting state functional connectivity link mindfulness meditation with reduced interleukin-6: A randomized controlled trial. Biological Psychiatry, 80(1), 53-61.
Cristofori, I., Bulbulia, J., Shaver, J. H., Wilson, M., Krueger, F., \& Grafman, J. (2016). Neural correlates of mystical experience. Neuropsychologia, 80, 212-220.

Crutchfield, R. S. (1955). Conformity and character. American Psychologist, 10(5), 191-198.

Dawes, C. T., \& Weinschenk, A. C. (2020). On the genetic basis of political orientation. Current Opinion in Behavioral Sciences, 34, 173-178.

Decety, J., Pape, R., \& Workman, C. I. (2018). A multilevel social neuroscience perspective on radicalization and terrorism. Social Neuroscience, 13(5), 511-529.

den Ouden, H. E., Kok, P., \& De Lange, F. P. (2012). How prediction errors shape perception, attention, and motivation. Frontiers in Psychology, 3, 548.

Dijksterhuis, A. P., Van Knippenberg, A. D., Kruglanski, A. W., \& Schaper, C. (1996). Motivated social cognition: Need for closure effects on memory and judgment. Journal of Experimental Social Psychology, 32(3), 254-270.

Douglas, K. M., \& Sutton, R. M. (2018). Why conspiracy theories matter: A social psychological analysis. European Review of Social Psychology, 29(1), 256-298.

Draganski, B., Gaser, C., Busch, V., Schuierer, G., Bogdahn, U., May, A. (2004). Neuroplasticity: Changes in grey matter induced by training. Nature, 427(6972), 311-312.

Essex, M. J., Thomas Boyce, W., Hertzman, C., Lam, L. L., Armstrong, J. M., Neumann, S. M., \& Kobor, M. S. (2013). Epigenetic vestiges of early developmental adversity: childhood stress exposure and DNA methylation in adolescence. Child Development, 84(1), 58-75.

Everson-Rose, S. A., Mendes de Leon, C. F., Bienias, J. L., Wilson, R. S., \& Evans, D. A. (2003). Early life conditions and cognitive functioning in later life. American Journal of Epidemiology, 158(11), 1083-1089.

Festinger, L. (1950). Informal social communication. Psychological Review, 57(5), 271-282.

Festinger, L. (1954). Motivations leading to social behavior. In M. R. Jones (Ed.), Nebraska Symposium on Motivation, 1954 (pp. 191-219). University of Nebraska Press.

Fischer, H., Amelung, D., \& Said, N. (2019). The accuracy of German citizens' confidence in their climate change knowledge. Nature Climate Change, 9(10), 776-780.

Fowler, J. H., Baker, L. A., \& Dawes, C. T. (2008). Genetic variation in political participation. American Political Science Review, 102(2), 233-248.

Friedman, E. M., Karlamangla, A. S., Gruenewald, T., Koretz, B., \& Seeman, T. E. (2015). Early life adversity and adult biological risk profiles. Psychosomatic Medicine, 77(2), 176-185. 


\section{A neurocognitive model of ideological thinking}

Friesen, A., Gruszczynski, M., Smith, K. B., \& Alford, J. R. (2020). Political attitudes vary with detection of androstenone. Politics and the Life Sciences, 39(1), 26-37.

Good, M., Inzlicht, M., \& Larson, M. J. (2015). God will forgive: Reflecting on God's love decreases neurophysiological responses to errors. Social Cognitive and Affective Neuroscience, 10(3), 357-363.

Goudarzi, S., Pliskin, R., Jost, J. T., \& Knowles, E. D. (2020). Economic system justification predicts muted emotional responses to inequality. Nature Communications, 11(1), 1-9.

Green, R., \& Douglas, K. M. (2018). Anxious attachment and belief in conspiracy theories. Personality and Individual Differences, 125, 30-37.

Gruenewald, T. L., Karlamangla, A. S., Hu, P., Stein-Merkin, S., Crandall, C., Koretz, B., \& Seeman, T. E. (2012). History of socioeconomic disadvantage and allostatic load in later life. Social Science do Medicine, 74(1), 75-83.

Haas, I. J., Baker, M. N., \& Gonzalez, F. J. (2017). Who can deviate from the party line? Political ideology moderates evaluation of incongruent policy positions in insula and anterior cingulate cortex. Social Justice Research, 30(4), 355-380.

Haas, I. J., \& Cunningham, W. A. (2014). The uncertainty paradox: Perceived threat moderates the effect of uncertainty on political tolerance. Political Psychology, 35(2), 291-302.

Haas, I. J., Warren, C., \& Lauf, S. J. (2020, January 30). Political neuroscience: Understanding how the brain makes political decisions. https://doi.org/10.31234/osf.io/kvzcf

Hagan, M. J., Roubinov, D. S., Adler, N. E., Boyce, W. T., \& Bush, N. R. (2016). Socioeconomic adversity, negativity in the parent child-relationship, and physiological reactivity: An examination of pathways and interactive processes affecting young children's physical health. Psychosomatic Medicine, 78 (9), 998-1007.

Haslam, S. A., \& Reicher, S. D. (2017). 50 years of "obedience to authority": From blind conformity to engaged followership. Annual Review of Law and Social Science, 13, 59-78.

Hasson, U., Ghazanfar, A. A., Galantucci, B., Garrod, S., \& Keysers, C. (2012). Brain-to-brain coupling: a mechanism for creating and sharing a social world. Trends in Cognitive Sciences, 16(2), 114-121.

Hatemi, P. K., \& McDermott, R. (2012a). The genetics of politics: Discovery, challenges, and progress. Trends in Genetics, 28(10), 525-533.

Hatemi, P. K., \& McDermott, R. (2012b). A neurobiological approach to foreign policy analysis: Identifying individual differences in political violence. Foreign Policy Analysis, 8(2), 111-129.
Hatemi, P. K., McDermott, R., Eaves, L. J., Kendler, K. S., \& Neale, M. C. (2013). Fear as a disposition and an emotional state: A genetic and environmental approach to out-group political preferences. American Journal of Political Science, 57(2), 279-293.

Hatemi, P. K., Medland, S. E., Klemmensen, R., Oskarsson, S., Littvay, L., Dawes, C., Verhulst, B., McDermott, R., Nørgaard, A. S., Klofstad, C., Christensen, K., Johannesson, M., Magnusson, P. K. E., Eaves, L. J., \& Martin, N. G. (2014). Genetic influences on political ideologies: Twin analyses of 19 measures of political ideologies from five democracies and genome-wide findings from three populations. Behavior Genetics, 44(3), 282-294.

Hein, G., Engelmann, J. B., \& Tobler, P. N. (2018). Pain relief provided by an outgroup member enhances analgesia. Proceedings of the Royal Society B: Biological Sciences, 285(1887), 20180501.

Heyes, C., Bang, D., Shea, N., Frith, C. D., \& Fleming, S. M. (2020). Knowing ourselves together: The cultural origins of metacognition. Trends in Cognitive Sciences, 24(5), 349-362.

Hibbing, J. R., Smith, K. B., \& Alford, J. R. (2014). Differences in negativity bias underlie variations in political ideology. Behavioral and Brain Sciences, 37(3), 297-307.

Hibbing, J. R., Smith, K. B., Peterson, J. C., \& Feher, B. (2014). The deeper sources of political conflict: Evidence from the psychological, cognitive, and neuro-sciences. Trends in Cognitive Sciences, 18(3), 111-113.

Hill, P. C., \& Williamson, W. P. (2005). The psychology of religious fundamentalism. Guilford Press.

Hölzel, B.K., Carmody, J., Evans, K.C., Hoge, E.A., Dusek, J. A., Morgan, L., Pitman, R.K., \& Lazar, S.W. (2009). Stress reduction correlates with structural changes in the amygdala. Social Cognitive and Affective Neuroscience, 5(1), 11-17.

Hommel, B., \& Colzato, L. S. (2010). Religion as a control guide: On the impact of religion on cognition. Zygon, 45(3), 596-604.

Hommel, B., \& Colzato, L. S. (2017). The social transmission of metacontrol policies: mechanisms underlying the interpersonal transfer of persistence and flexibility. Neuroscience \& Biobehavioral Reviews, 81(Part A), 43-58.

Hommel, B., Colzato, L. S., Scorolli, C., Borghi, A. M., \& van den Wildenberg, W. P. (2011). Religion and action control: Faith-specific modulation of the Simon effect but not stopsignal performance. Cognition, 120(2), 177-185.

Hughes, B. L., Camp, N. P., Gomez, J., Natu, V. S., GrillSpector, K., \& Eberhardt, J. L. (2019). Neural adaptation to faces reveals racial outgroup homogeneity effects in early perception. Proceedings of the National Academy of Sciences, 116(29), 14532-14537. 


\section{Leor Zmigrod}

Hyman, H. (1959). Political socialization. Free Press.

Inzlicht, M., McGregor, I., Hirsh, J. B., \& Nash, K. (2009). Neural markers of religious conviction. Psychological Science, 20(3), 385-392.

Inzlicht, M., Tullett, A. M., \& Good, M. (2011). The need to believe: a neuroscience account of religion as a motivated process. Religion, Brain \& Behavior, 1(3), 192-212.

Israel, S., Hasenfratz, L., \& Knafo-Noam, A. (2015). The genetics of morality and prosociality. Current Opinion in Psychology, 6, 55-59.

Jost, J. T., \& Banaji, M. R. (1994). The role of stereotyping in system-justification and the production of false consciousness. British Journal of Social Psychology, 33(1), 1-27.

Jost, J. T., Glaser, J., Kruglanski, A. W., \& Sulloway, F. J. (2003). Political conservatism as motivated social cognition. Psychological Bulletin, 129(3), 339-375.

Jost, J. T., Nam, H. H., Amodio, D. M., \& Van Bavel, J. J. (2014). Political neuroscience: The beginning of a beautiful friendship. Political Psychology, 35(S1), 3-42.

Jost, J. T., Nosek, B. A., \& Gosling, S. D. (2008). Ideology: Its resurgence in social, personality, and political psychology. Perspectives on Psychological Science, 3(2), 126-136.

Kanai, R., Feilden, T., Firth, C., \& Rees, G. (2011). Political orientations are correlated with brain structure in young adults. Current Biology, 21(8), 677-680.

Kaplan, G. A., Turrell, G., Lynch, J. W., Everson, S. A., Helkala, E. L., \& Salonen, J. T. (2001). Childhood socioeconomic position and cognitive function in adulthood. International Journal of Epidemiology, 30(2), 256-263.

Kleitman, S., Hui, J. S. W., \& Jiang, Y. (2019). Confidence to spare: individual differences in cognitive and metacognitive arrogance and competence. Metacognition and Learning, 14(3), 479-508.

Krosch, A. R., \& Amodio, D. M. (2019). Scarcity disrupts the neural encoding of Black faces: A socioperceptual pathway to discrimination. Journal of Personality and Social Psychology, 117(5), 859-875.

Kruglanski, A. W., Gelfand, M. J., Bélanger, J. J., Sheveland, A., Hetiarachchi, M., \& Gunaratna, R. (2014). The psychology of radicalization and deradicalization: How significance quest impacts violent extremism. Political Psychology, 35(Suppl. 1), 69-93.

Ksiazkiewicz, A., \& Krueger, R. F. (2017). The role of genes and environments in linking the need to evaluate with political ideology and political extremity. Social Justice Research, 30(4), 381-407.
Ksiazkiewicz, A., Ludeke, S., \& Krueger, R. (2016). The role of cognitive style in the link between genes and political ideology. Political Psychology, 37(6), 761-776.

Lassiter, G. D., Briggs, M. A., \& Slaw, R. D. (1991). Need for cognition, causal processing, and memory for behavior. Personality and Social Psychology Bulletin, 17(6), 694-700.

Leong, Y. C., Radulescu, A., Daniel, R., DeWoskin, V., \& Niv, Y. (2017). Dynamic interaction between reinforcement learning and attention in multidimensional environments. Neuron, 93(2), 451-463.

Leong, Y. C., Chen, J., Willer, R., \& Zaki, J. (2020). Conservative and liberal attitudes drive polarized neural responses to political content. Proceedings of the National Academy of Sciences, 117(44), 27731-27739.

Lewkowicz, D. J., \& Ghazanfar, A. A. (2009). The emergence of multisensory systems through perceptual narrowing. Trends in Cognitive Sciences, 13(11), 470-478.

Locke, E. (2000). Motivation, cognition, and action: An analysis of studies of task goals and knowledge. Applied Psychology, 49(3), 408-429.

Lupien, S. J., Maheu, F., Tu, M., Fiocco, A., \& Schramek, T. E. (2007). The effects of stress and stress hormones on human cognition: Implications for the field of brain and cognition. Brain and Cognition, 65(3), 209-237.

Maguire, E. A., Gadian, D. G., Johnsrude, I. S., Good, C. D., Ashburner, J., Rackowiak, R. S. J., \& Frith, C. D. (2000). Navigation-related structural change in the hippocampi of taxi drivers. Proceedings of the National Academy of Sciences, 97(8), 4398-4403.

Martin, R., \& Hewstone, M. (2001). Conformity and independence in groups: Majorities and minorities. In M. A. Hogg \& R.S. Tindale (Eds.), Blackwell Handbook of Social Psychology: Group Processes (pp. 209-234). Blackwell Publishers.

McEwen, B. S. (2012). Brain on stress: how the social environment gets under the skin. Proceedings of the National Academy of Sciences, 109(Suppl. 2), 17180-17185.

McGregor, I., Nash, K., Mann, N., \& Phills, C. E. (2010). Anxious uncertainty and reactive approach motivation (RAM). Journal of Personality and Social Psychology, 99(1), 133-147.

McGregor, I., Zanna, M. P., Holmes, J. G., \& Spencer, S. J. (2001). Compensatory conviction in the face of personal uncertainty: going to extremes and being oneself. Journal of Personality and Social Psychology, 80(3), 472-488.

Milgram, S. (1963). Behavioral study of obedience. Journal of Abnormal and Social Psychology, 67(4), 371-378. 


\section{A neurocognitive model of ideological thinking}

Milgram, S. (1974). Obedience to authority: An experimental view. Harper \& Row.

Molenberghs, P., \& Louis, W. R. (2018). Insights from fMRI studies into ingroup bias. Frontiers in Psychology, 9, 1868.

Morris, M. W., Savani, K., \& Fincher, K. (2019).

Metacognition fosters cultural learning: Evidence from individual differences and situational prompts. Journal of Personality and Social Psychology, 116(1), 46-68.

Nam, H. H., Jost, J. T., \& Feldman, S. (2017). The neurobiology of fairness and social justice: An introduction. Social Justice Research, 30(4), 289-299.

Nam, H. H., Jost, J. T., Kaggen, L., Campbell-Meiklejohn, D., \& Van Bavel, J. J. (2018). Amygdala structure and the tendency to regard the social system as legitimate and desirable. Nature Human Behaviour, 2(2), 133-138.

Norenzayan, A., \& Shariff, A. F. (2008). The origin and evolution of religious prosociality. Science, 322(5898), 58-62.

Oskarsson, S., Cesarini, D., Dawes, C. T., Fowler, J. H., Johannesson, M., Magnusson, P. K., \& Teorell, J. (2015). Linking genes and political orientations: Testing the cognitive ability as mediator hypothesis. Political Psychology, 36(6), 649-665.

Oxley, D. R., Smith, K. B., Alford, J. R., Hibbing, M. V., Miller, J. L., Scalora, M., Hatemi, P. K., \& Hibbing, J. R. (2008). Political attitudes vary with physiological traits. Science, 321(5896), 1667-1670.

Paglieri, F., Borghi, A. M., Colzato, L. S., Hommel, B., \& Scorolli, C. (2013). Heaven can wait. How religion modulates temporal discounting. Psychological Research, 77(6), $738-747$.

Pennycook, G., Cheyne, J. A., Barr, N., Koehler, D. J., \& Fugelsang, J. A. (2014). Cognitive style and religiosity: The role of conflict detection. Memory \& Cognition, 42(1), 1-10.

Pessoa, L. (2009). How do emotion and motivation direct executive control? Trends in Cognitive Sciences, 13(4), $160-166$.

Pessoa, L., \& Engelmann, J. B. (2010). Embedding reward signals into perception and cognition. Frontiers in Neuroscience, 4, 17.

Plessow, F., Fischer, R., Kirschbaum, C., \& Goschke, T. (2011). Inflexibly focused under stress: Acute psychosocial stress increases shielding of action goals at the expense of reduced cognitive flexibility with increasing time lag to the stressor. Journal of Cognitive Neuroscience, 23(11), 3218-3227.

Posner, M. I., \& Rothbart, M. K. (2018). Temperament and brain networks of attention. Philosophical Transactions of the Royal Society B: Biological Sciences, 373(1744), 20170254.
Richins, M. T., Barreto, M., Karl, A., \& Lawrence, N. (2019). Empathic responses are reduced to competitive but not noncompetitive outgroups. Social Neuroscience, 14(3), 345-358.

Robbins, T. W., \& Costa, R. M. (2017). Habits. Current Biology, 27(22), R1200-R1206.

Rollwage, M., Dolan, R. J., \& Fleming, S. M. (2018). Metacognitive failure as a feature of those holding radical beliefs. Current Biology, 28(24), 4014-4021.

Rollwage, M., Zmigrod, L., de-Wit, L., Dolan, R. J., \& Fleming, S. M. (2019). What underlies political polarization? A manifesto for computational political psychology. Trends in Cognitive Sciences, 23(10), 820-822.

Sale, A., Berardi, N., \& Maffei, L. (2014). Environment and brain plasticity: towards an endogenous pharmacotherapy. Physiological Reviews, 94(1), 189-234.

Sallis, H., Smith, G. D., \& Munafo, M. R. (2018). Genetics of biologically based psychological differences. Philosophical Transactions of the Royal Society B: Biological Sciences, 373(1744), 20170162.

Schoofs, D., Preuß, D., \& Wolf, O. T. (2008). Psychosocial stress induces working memory impairments in an n-back paradigm. Psychoneuroendocrinology, 33(5), 643-653.

Schreiber, D., Fonzo, G., Simmons, A. N., Dawes, C. T., Flagan, T., Fowler, J. H., \& Paulus, M. P. (2013). Red brain, blue brain: Evaluative processes differ in Democrats and Republicans. PLOS ONE, 8(2), e52970.

Shils, E. (1958). Ideology and Civility: On the Politics of the Intellectual. Sewanee Review, 66(3), 450-480.

Sinclair, A. H., Stanley, M., \& Seli, P., Ph.D. (2019, December 21). Closed-minded cognition: Right-wing authoritarianism is negatively related to belief updating. https://doi.org/10.31234/ osf.io/94a $7 \mathrm{v}$

Smith, K. B., \& Warren, C. (2020). Physiology predicts ideology. Or does it? The current state of political psychophysiology research. Current Opinion in Behavioral Sciences, 34, 88-93.

Sosis, R., \& Alcorta, C. (2003). Signaling, solidarity, and the sacred: The evolution of religious behavior. Evolutionary Anthropology: Issues, News, and Reviews: Issues, News, and Reviews, 12(6), 264-274.

Springer, K. W., Sheridan, J., Kuo, D., \& Carnes, M. (2007). Long-term physical and mental health consequences of childhood physical abuse: Results from a large populationbased sample of men and women. Child Abuse \& Neglect, 31(5), 517-530.

Suhay, E., Brandt, M. J., \& Proulx, T. (2017). Lay belief in biopolitics and political prejudice. Social Psychological and Personality Science, 8(2), 173-182. 


\section{Leor Zmigrod}

Sullivan, D., Landau, M. J., \& Rothschild, Z. K. (2010). An existential function of enemyship: Evidence that people attribute influence to personal and political enemies to compensate for threats to control. Journal of Personality and Social Psychology, 98(3), 434-449.

Thórisdóttir, H., \& Jost, J. T. (2011). Motivated closedmindedness mediates the effect of threat on political conservatism. Political Psychology, 32(5), 785-811.

Trofimova, I. (2016). The interlocking between functional aspects of activities and a neurochemical model of adult temperament. In M. C. Arnold (Ed.), Temperaments: Individual differences, social and environmental influences and impact on quality of life (pp. 77-147). Nova Science.

Trofimova, I., \& Robbins, T. W. (2016). Temperament and arousal systems: a new synthesis of differential psychology and functional neurochemistry. Neuroscience \& Biobehavioral Reviews, 64, 382-402.

Trofimova, I., Robbins, T. W., Sulis, W. H., \& Uher, J. (2018). Taxonomies of psychological individual differences: Biological perspectives on millennia-long challenges. Philosophical Transactions of the Royal Society B: Biological Sciences, 373(1744), 20170152.

Twito, L., \& Knafo-Noam, A. (2020). Beyond culture and the family: Evidence from twin studies on the genetic and environmental contribution to values. Neuroscience \& Biobehavioral Reviews, 112, 135-143.

Uher, J. (2018). Taxonomic models of individual differences: a guide to transdisciplinary approaches. Philosophical Transactions of the Royal Society B: Biological Sciences, 373(1744), 20170171.

van Elk, M., \& Aleman, A. (2017). Brain mechanisms in religion and spirituality: An integrative predictive processing framework. Neuroscience \& Biobehavioral Reviews, 73, 359-378.

van Prooijen, J. W., \& Acker, M. (2015). The influence of control on belief in conspiracy theories: Conceptual and applied extensions. Applied Cognitive Psychology, 29(5), 753-761.

van Prooijen, J. W., Douglas, K. M., \& De Inocencio, C. (2018). Connecting the dots: Illusory pattern perception predicts belief in conspiracies and the supernatural. European Journal of Social Psychology, 48(3), 320-335.

Verplanken, B. (1993). Need for cognition and external information search: Responses to time pressure during decisionmaking. Journal of Research in Personality, 27(3), 238-252.

Villa, D. (Ed.). (2000). The Cambridge companion to Hannah Arendt. Cambridge University Press.
Wickrama, K. A. S., Conger, R. D., \& Abraham, W. T. (2005) Early adversity and later health: The intergenerational transmission of adversity through mental disorder and physical illness. Journals of Gerontology Series B: Psychological Sciences and Social Sciences, 60, S125-S129.

Zaller, J. (1992). The nature and origins of mass opinion. Cambridge University Press.

Zhong, W., Cristofori, I., Bulbulia, J., Krueger, F., \& Grafman, J. (2017). Biological and cognitive underpinnings of religious fundamentalism. Neuropsychologia, 100, 18-25.

Zmigrod, L. (2020a). A psychology of ideology: Unpacking the psychological structure of ideological thinking. https://doi.org/ 10.31234/osf.io/ewy9t

Zmigrod, L. (2020b). The role of cognitive rigidity in political ideologies: theory, evidence, and future directions. Current Opinion in Behavioral Sciences, 34, 34-39.

Zmigrod, L., Eisenberg, I., Bissett, P., Robbins, T. W., \& Poldrack, R. (2021). The cognitive and perceptual correlates of ideological attitudes: A data-driven approach. Philosophical Transactions of the Royal Society B, 376(1822), 20200424.

Zmigrod, L., Rentfrow, P. J., \& Robbins, T. W. (2018). Cognitive underpinnings of nationalistic ideology in the context of Brexit. Proceedings of the National Academy of Sciences, 115(19), E4532-E4540.

Zmigrod, L., Rentfrow, P. J., \& Robbins, T. W. (2019). Cognitive inflexibility predicts extremist attitudes. Frontiers in Psychology, 10, 989.

Zmigrod, L., Rentfrow, P. J., \& Robbins, T. W. (2020). The partisan mind: Is extreme political partisanship related to cognitive inflexibility? Journal of Experimental Psychology: General, 149(3), 407-418.

Zmigrod, L., Rentfrow, P. J., Zmigrod, S., \& Robbins, T. W. (2019). Cognitive flexibility and religious disbelief. Psychological Research, 83(8), 1749-1759.

Zmigrod, L., \& Tsakiris, M. (2021). Computational and neurocognitive approaches to the political brain: Key insights and future avenues for political neuroscience. Philosophical Transactions of the Royal Society B, 376(1822), 20200130.

Zmigrod, L., Zmigrod, S., Rentfrow, P. J., \& Robbins, T. W. (2019). The psychological roots of intellectual humility: The role of intelligence and cognitive flexibility. Personality and Individual Differences, 141, 200-208.

Zmigrod, L., \& Goldenberg, A. (2021). Cognition and Emotion in Extreme Political Action: Individual Differences and Dynamic Interactions. Current Directions in Psychological Science. https://doi.org/10.1177/0963721421993820. 